\title{
Study on Current Situation, Causes and Countermeasures of the Education Model of "Key Competencies" in Primary and Secondary Schools in China
}

\author{
He Jiangxin, Huo Xuan \\ Xi'an University of Science and Technology \\ Xi'an, Shaanxi, 710054
}

\begin{abstract}
The purpose of this paper is to propose corresponding countermeasures for the development status of "key competencies". This paper selects literatures in this field for study and analysis through the literature research method, carries out the questionnaire survey and data collation, sums up information of relevant schools and parents through the questionnaire survey method, finds the main factors that affect the development of "key competencies" in China based on the collation and summary of the document literature and the above data, and draws a conclusion. The survey shows that lack of the evaluation mechanism for old family education concepts and failure to supervise the management of extracurricular tutoring in primary and secondary schools are the main factors. This paper proposes countermeasures such as renewing education concepts of families, strengthening the evaluation mechanism construction and standardizing extracurricular tutoring.
\end{abstract}

Keywords-Key competencies; Quality education; Countermeasures

\section{INTRODUCTION}

Since the reform and opening up, all aspects of China's economy and society have developed rapidly, education has also achieved unprecedented development in primary and secondary schools and is moving towards internationalization. However, it is worthy of concern that there are some problems in our primary and secondary education, for example, quality education is always difficult to carry out, let alone "key competencies". Then, what causes these good educational models and ideas difficult to be implemented? This paper will focus on this problem, explore the path and significance of implementing "key competencies", and seek advice from experts.

\section{EXPLORATION OF THE DEVELOPMENT OF QUALITY EDUCATION IN PRIMARY AND SECONDARY SCHOOLS SINCE REFORM AND OPENING UP}

In May 1985, comrade Deng Xiaoping mentioned: "Our country, the national strength and the after-strength of economic development are more and more depending on the quality of the workers, depending on the quantity and quality of the intellectuals". This is the first time the train of thought of "quality" education was mentioned at the first National Conference on Educational Work, and quality education started in China. In the background of this era, there are more and more researches on "quality" and "national quality" in the theoretical circle. At the same time, some educational reform experimental models, which reflect the thought of quality education, have appeared on the front line of education and teaching. This provides certain theoretical support for the later development of quality education in China, and also lays a practical foundation.

On February 13, 1993, the Central Committee of the Communist Party of China and the State Council formulated and promulgated the Outline for Reform and Development of Education in China, which expressly stipulates that "primary and secondary schools should shift from 'exam-oriented education' to the improvement of national quality". In the Outline, the word "quality" is mentioned for more than 20 times. In 1994, comrade Li Lanqing put forward at the National Conference on Education Work: "Basic education must shift from 'exam-oriented education' to 'quality education'." Then in August of the same year, some opinions of the CPC Central Committee on Further Strengthening and Improving School Moral Education was promulgated. The Opinions clearly states that "Enhance quality education that adapts to the development of the times, the social progress, and the new requirements and urgent needs of establishing a socialist market economy system". The concept of quality education was formally written into the central document for the first time. Since the concept of quality education was formally used in 1994, quality education has been implemented for more than 20 years in our country. In June 1994, the second National Conference on Educational Work was held. At this working conference, the construction of the pilot area for quality education reform was first put forward. On October 29, 1997, a regional climax of quality education emerged. The first batch of ten pilot areas for quality education was set up in the country, and some provincial quality education pilot areas were also started to build at the provincial level. In 1999, the Education Revitalization Action Plan for the 21st Century was approved by the State Council and formulated and promulgated by the Ministry of Education. 
The document pointed out that the "cross-century quality education project" should be implemented to realize the overall development of quality education. In the same year, the Central Committee of the Communist Party of China and the State Council convened a National Conference on Education Work, and promulgated the Decision on Deepening Education Reform and Promoting Quality Education in an Allround Way. With quality education as the theme, the conference determined the main connotation of quality education, pointed out the ways and the main measures to implement quality education, and further determined the great significance of quality education. Quality education began to enter a new situation of key breakthrough and full implementation pushed by the state, and became an important strategic decision of the party and the state on education work. A new round of basic education curriculum reform was initiated. In the new Law on Compulsory Education in 2006, quality education was written to the law for the first time, and it clearly stipulated that compulsory education "must implement quality education". Up to the autumn of 2009, ordinary high schools in 25 provinces across the country entered the new curriculum reform stage. As the core of quality education, the new curriculum reform was fully implemented in the compulsory education stage, which played a key role in the overall advancement of quality education.

\section{DEVELOPMENT STATUS OF KEY COMPETENCIES}

Since the 21st Century, information and communication technology has been developing rapidly and widely applied, and human society has quickly entered the information age. As we all know, technology and education are dialectically unified. On the one hand, the development of technology depends on education. Without the deepening of education, it is impossible to produce advanced technology; on the other hand, the development of education also relies on technology, for example, through the Internet and other advanced media, education is rapidly expanding in efficiency and popularity. In line with the development of information technology, education is transformed from quality education to key competency education. The information age has determined that key competencies are the development direction of primary and secondary education.

\section{A. The proposal of "key competencies" and its connotation}

The so-called "key competencies refer to the necessary characters and key competencies gradually formed by the students in the process of accepting the education of corresponding learning stages to adapt to the needs of social development and the lifelong development of the individual. " It is the comprehensive performance of the students' knowledge, ability and attitude, and has the characteristics of continuity and periodicity of develop. It is the most critical and important basic competency that all students should have. In our country, the socialist core values contain judgment criteria of three levels: state, society and citizen. Based on the reality of our country, the development of "key competencies" in China is centered on the socialist core values, and it should be trained, molded and maintained through school education.
The human theory of Marxism is the core of the theory of all-round development of human beings. The party's educational policy is guided by the theory of Marxism. In order to cultivate "people of all-round development", "the construction system of key competencies in China mainly includes three aspects, such as cultural foundation, independent development and social participation, which are embodied as six competencies, such as humanistic connotation, scientific spirit, learning how to learn, healthy life, responsibility and practice innovation" . The competencies are interrelated, complementary and mutually reinforcing, and function together in the cultivation process of "all-round development of people". According to the specific characteristics of the students of different ages, the overall framework is used as the main basis, and the specific requirements for the specific situations of each learning stage can be further proposed.

The establishment and development of key competency system is a worldwide trend in the contemporary society. The structural model of "key competencies" was first proposed by the Organization for Economic Cooperation and Development (OECD) at the beginning of the 21st Century. The establishment of this model is mainly to solve one problem: what are the most core knowledge, abilities and emotional attitudes that the students cultivated in the 21st Century should have, so as to successfully integrate into the future society, meet the individual self-actualization needs and promote the social development?

\section{B. Development status of key competencies at abroad}

At abroad, the construction of "key competencies" is mainly represented by several large organizations.

The first is the construction of key competence framework by the Organization for Economic Cooperation and Development (OECD). The "Definition and Selection of Competencies: Theoretical and Conceptual Foundations" project (DeSeCo for short) launched by the Organization for Economic Cooperation and Development in December 1997 has a far-reaching impact on the establishment of key competency system in the world. OECD has determined three competencies, namely the ability to interact utility tools, the ability to interact effectively in heterogeneous groups and the ability of independent action. The three are interconnected and integrated, and this characteristic is the result of constant change to adapt to the needs of different situations. From the point of view of its functions, the DeSeCo project makes a concrete expression of the functions of core competencies, namely, "helping the society and individuals to obtain valuable results output and the individual to meet the important needs of various social life fields", which is of great significance to individual development. The DeSeCo project examines key competencies from a wide range of interdisciplinary perspectives to determine a set of key competency indicators. These indicators are essential for building a harmonious society and living a happy life in our current social life. At the same time, the competency indicators are of great significance in coping with the current and future technological changes and the challenge of globalization. Of course, the DeSeCO project group simply 
points out the connotation of key competencies, that is, it includes the application of cognitive and practical skills, innovation ability and attitude, motivation and values, which transcends the knowledge and skills that are directly imparted. Meanwhile, it considers reflective thinking and action as the core of the education model.

The second is the EU's key competency framework. In December 2016, the European Parliament and the Council of the European Union adopted a proposal on key competencies. The proposal pointed out that "the key competency framework is divided into eight key competency systems, namely native language, foreign language, mathematics and science and technology competency, information competency, learning ability, civic and social competency, entrepreneurship and artistic competency." Key competencies are defined as "a collection of a series of knowledge, skills and attitudes necessary for each person to develop oneself, integrate into the society, and be competent for a job in a knowledge-based society". This is the second famous framework of key competencies in the world. It is the mainstay of the European Union's education development over the last ten years, and constitutes the education reform guidance system together with the life-long learning strategy to promote the reform and development of education. The framework not only draws on the experience of OECD and DeSeCo, but also fully embodies the characteristics and development needs of European education. It is mainly to develop the essential key competencies in the development of the European knowledge society, become the template for the future education goal, and also provide a theoretical reference for the establishment and development of key competencies of the EU member countries.

The third is the "21st Century learning framework" of the United States. In 1991, the United States Department of Labour established a high-end expert work committee, which mainly completed two tasks: first, to determine the working skills required in the 21st Century; second, to assess whether American schools are teaching these skills. In 2002, under the convening of the United States Department of Education, the influential enterprises and private research institutions, such as Apple, Microsoft, DELL and the National Education Association, established the "21st Century Skills Partnership", which systematically studied the skills needed to adapt to the information age and the knowledge economy. These skills can be divided into three categories: the first is learning and innovative skills, the second is information, media and technical skills, and the third is life and career skills. To sum up, it includes two meanings: it is a kind of advanced skill or competency, its corresponding category is "basic skills"; second, it is associated with the situation, and it is the product of the application of knowledge and skills in the life and work situation of the 21 st Century. These skills combine and promote each other. From this, we can see that the "21st Century learning framework" of the United States has clear thinking, strong operability and complete organization, which is conducive to the curriculum and teaching reform in schools and school districts, and embodies distinct characteristics of "top-down" and the pursuit of education democracy.

\section{The development of key competencies in China and cause analysis}

Quality education is the foundation of key competencies, and key competencies are the promotion of quality education. Since the reform and opening up, the party and the government have always attached great importance to primary and secondary school education and embarked on the path of promoting the reform and development of education by means of curriculum reform.

(1) The development of key competencies in China. From the provision of conditions for educators, the competencies of educators themselves and organizational leadership, in June 1999, the Central Committee of the Communist Party of China and the State Council promulgated the Decision on Deepening Education Reform and Promoting Quality Education in an Allround Way; in 2001, the new century basic education curriculum reform was initiated. In May 2010, the Central Committee of the Communist Party of China and the State Council promulgated the Outline of the State Medium - and Long-term Education Reform and Development Plan (20102020). From basic education to higher education, the outline has fully planned the overall blueprint for education development in an all-round way. In 2011, the state promulgated new standards for various disciplines in good time, and began to implement in the following autumn. From this trend, our country is at the key stage of the development of new curriculum reform. People focus on the "deep-water area" of curriculum reform, so the curriculum reform has also entered a stage of high quality and continuous development. The ultimate goal is to achieve the overall improvement of education quality. On this basis, China proposes to set up a key competence curriculum system suitable for the national conditions. In 2014, the Ministry of Education developed and issued Opinions on Comprehensively Deepening Curriculum Reform and Implementing the Fundamental Task of Morality Education, which stated that "The Ministry of Education should organize research and put forward the key competency system of the students in each learning stage and make clear the necessary characters and key competencies that students should have to adapt to lifelong development and social development". It sets the tune for the key competencies of primary and secondary school students from the height of education authorities; On February 22, 2016, the state announced a draft for opinions on the development of key competencies of Chinese students and sought advice from the whole society, and finally summed up nine competencies, namely social responsibility, national identity, international understanding, cultural background, scientific spirit, aesthetic interest, physical and mental health, learning how to learn and practice innovation. In order to achieve the goal of "all-round development of people", on the morning of September 13, 2016, the research results presentation on Chinese students' development of key competencies was held at Beijing Normal University. The experts and scholars of the educational and psychological circles, the personnel of the administrative department of education and the first-line educators participated in the conference. The conference pointed out that the key competencies of the students in our country mainly include the key competencies of three categories and six aspects, namely, cultural foundation (humanistic connotations, 
scientific spirit), independent development (learning how to learn, healthy life) and social participation (responsibility, practice innovation). The Affiliated Primary School of Tsinghua University summed up the previous educational experience, combined with the cognitive characteristics of primary school students, and proposed that the development of primary school students include five key competencies, including physical health, aspiration in learning, world sentiment, aesthetic taste and learning to change; Beijing Normal University is the leader of the study of basic education teaching theory in China. Professor Zhu Hongqi's The Concept and Nature of Key Competencies (Journal of East China Normal University Education Science Edition, Issue No. 1 in 2016) briefly combs the formation process of the concept, and points out the four essential differences between key competencies and general competencies. In addition, some scholars have pointed out that key competencies are integrated interdisciplinary and transferable from the level of evaluation methods, but because a large number of tacit knowledge and attitude factors bring difficulties to the implementation and evaluation of curriculum, so they call for the establishment of monitoring and evaluation system based on "large data".

However, influenced by many factors such as culture, history or values, the implementation of quality education and key competencies in China is always difficult, and it still has a long way to go. The reality is often that the education authorities are implementing while the schools and parents are perfunctory. It can be said that "where there are policies, there are countermeasures", and it is difficult for the primary and secondary schools, parents and the competent departments to truly carry out key competencies. The reason is that this situation has deep historical soil and real living conditions.

(2) Analysis on the reasons why it is difficult to promote key competencies in primary and secondary schools in China. Although a series of rules and regulations have been promulgated to promote the implementation of quality education in the system and regulations, the quality education of primary and secondary schools in our country cannot fully adapted to the demands of the new age because of the old education concept, the absence of educational evaluation mechanism and the oversight of supervision.

First of all, the concept of family education is obsolete. Quality education has become a mere formality. The fact that exam-oriented education has not been changed in essence is the actual situation of education mode in primary and secondary schools in China. There is no doubt that Chinese families attach great importance to their children's education. Their education expenditure on children is the world's leading level. The average education expenditure of parents in the world is shown in Figure 1:

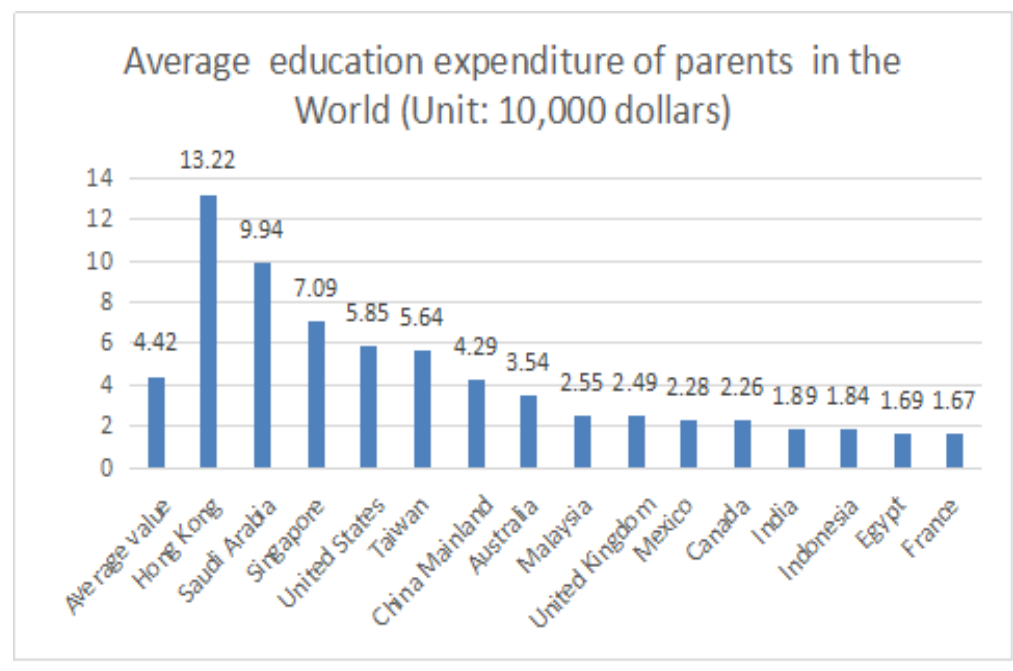

Fig. 1. Average education expenditure of parents in the world (unit: 10,000 dollars)

(Data source: HSBC Global Education Report 2017)

From the figure above, we can see that the education expenditure of Hongkong is the first and that of the mainland is in the forefront. From the situation of private tutoring in other countries, the education expenditure of Chinese families is also ahead of them, as shown in Figure 2: 


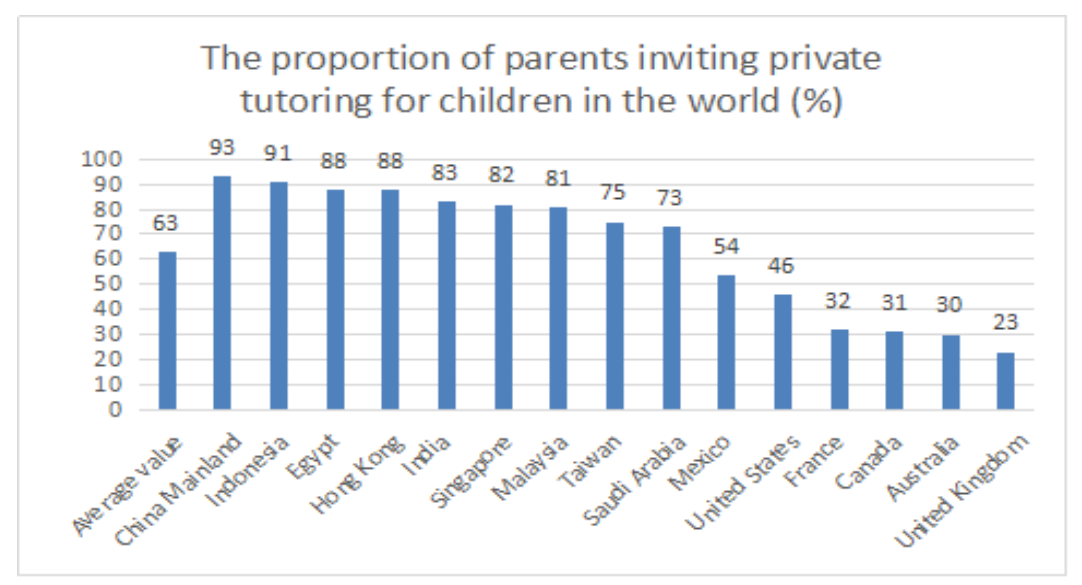

Fig. 2. The proportion of parents inviting private tutoring for children in the world (\%)

From the data in the figure above, we can see that the proportion of private tutoring in mainland China is the highest, which clearly shows the importance attached by our parents to education. However, there is something else in this regard, because they value not the overall development of the next generation, but the ability to take examinations. Of course, no one wants their children to suffer so much. In addition to the uneven distribution of high quality education resources, employment difficulty is the biggest worry. Therefore, most of these practices are inevitable.

Secondly, the lack of educational evaluation mechanism. Because of the traditional single educational evaluation system in our country, the quality of students is judged through the achievement of the students' cultural class. This standard leads to the situation that although Chinese families attach great importance to education, most of them only work hard on children's mathematics, physics, chemistry and other similar cultural knowledge, so it is difficult to play a substantial role in the implementation of quality education. In order to change the current situation of quality education which is difficult to implement in an all-round way and let quality education really come true, the key is to constantly deepen curriculum reform, establish and improve the quality education evaluation system mechanism, weaken the core position of exam-oriented education in the course of education and teaching, and truly let the students achieve the all-round development of morality, intelligence, physique and aesthetic.

Finally, the supervision of primary and secondary school extracurricular guidance was neglected. In China, extracurricular catch-up classes are common among primary and secondary school students, and there are various catch-up classes. Generally speaking, the charges of these catch-up classes are very high, which is far beyond the reach of ordinary families. However, because the parents do not want their children to lose at the starting line, some ordinary families try their best to let their children study in these catchup classes. One problem that needs to be clarified is whether it is a normal phenomenon to make up classes for primary and secondary school students. If so, should the government and the society encourage and advocate these devotees who work hard for the cause of education? If not, whether to hold responsible and pass legislation to prevent similar phenomenon from happening? Both the government and the society seem to keep a blind eye to these problems, because making up classes is in common sense or "the law does not punish numerous offenders". However, apart from the high cost of making up classes, who will be responsible for squeezing students' extracurricular time and damaging their physical and mental health? The most critical problem is that many educators themselves knowingly violate the law, how can they cultivate the students' sense of rule of law?

As mentioned above, for practical and historical reasons, the key competencies of primary and middle schools in China and its theoretical research are still in the initial stage, and it will still take time to implement it in an all-round way.

\section{COUNTERMEASURES FOR THE DEVELOPMENT OF KEY COMPETENCIES OF PRIMARY AND MIDDLE SCHOOLS IN CHINA}

The construction of key competencies has become the key and difficult point of education reform in China. How to promote the development of key competencies and promote education reform in primary and secondary schools can be mainly started from the following three aspects:

\section{A. Renewing educational concepts}

Education is a reflection of economic foundation and belongs to superstructure. Fortunately, with the increase of residents' income level, education consumption has also been further upgraded. Some new generation parents no longer take the "score only theory" as the main criterion for their children's learning, and begin to pay more attention to the cultivation of their children's quality and pursue nonexamination-oriented education content. According to the survey data, the parents' attitudes towards quality education are shown in Figure 3: 


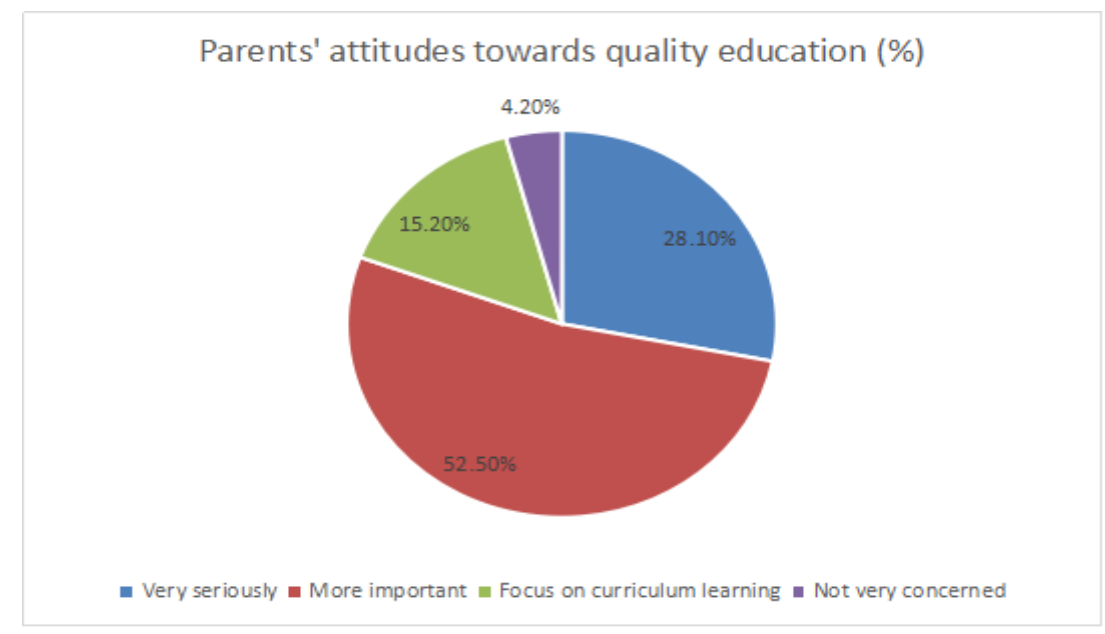

Fig. 3. Parents' attitudes towards quality education (\%)

(Data source: survey data)

Research data show that the proportion of Chinese parents valuing quality education is as high as $80 \%$. This also shows that the construction and development of quality education in China has entered a new stage. The quality education in China has aroused the attention of the parents. This has promoted the development of quality education to a certain extent, and also provided a strong support for the implementation of quality education.

\section{B. Consolidating the education evaluation system mechanism}

As the traditional education evaluation system in our country is too single, which uses examination as the only means to test students and uses scores as the only standard to evaluate students, it has limited the development of quality education to a great extent. In recent years, in order to solve this problem, relevant departments of our country has promulgated several policy opinions related to quality education reform and evaluation reform. In September 2014, the State Council promulgated the Implementation Opinions on Deepening Examination and Admission System Reform, and regarded comprehensive quality evaluation as the important reference standard for students to enter a higher school and graduate. In December of the same year, the Ministry of Education promulgated the Opinions on Strengthening and Improving Comprehensive Quality Evaluation of Ordinary High School Students. The Opinions required that from 2015, the provinces (districts and cities) should put forward the basic requirements for comprehensive quality evaluation of high school students and release specific measures to provide important reference basis for the specific enrollment and admission process of colleges and universities. And comprehensive quality evaluation should be included in the reform of college entrance examination. Through the reform of evaluation system, that is, to increase the proportion of the evaluation on quality education of students in the evaluation of each component and its overall level, this can greatly promote the development of quality education. The comprehensive quality evaluation system is shown in the table below:

level

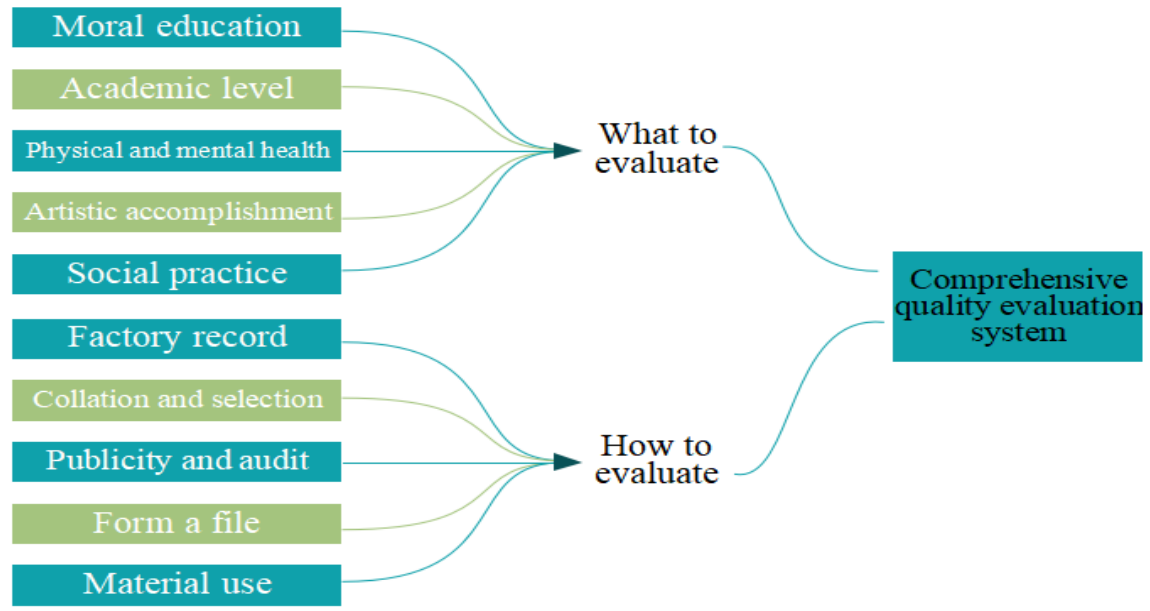

Fig. 4. Comprehensive Quality Evaluation System 


\section{Strengthening the rule of law in primary and secondary school education and enhancing the rule of law of the whole nation.}

The rule of law is the basic trend of social development. Since the 18th National Congress of the Communist Party of China, education rule of law has become a new hot spot in education. As pointed out in Peoples Network, the object and orientation of China's current rule of law education is not clear. The current rule of law education in China is more about the dissemination of legal knowledge than about the nurturance education of teenagers ' rule of law consciousness and belief. But the basic goal of the rule of law education for teenagers is to help students transform their values through their understanding and comprehension of the rules of law, and become responsible citizens with the concept of rule of law rather than simple understanding and memory of knowledge; at the same time, the orientation of the rule of law education in China is not clear, and the relationship between rule of law education and ideological and moral education, safety education and anti-corruption education has not been clarified. However, these are closely related to the consciousness of rule of law of the educators, families and the whole society. Only by improving the consciousness of rule of law of the whole society, the whole nation and the whole country can the concept of rule of law of the primary and middle school students be fundamentally improved. The CPC Central Committee's Decision on Several Major Issues Concerning Comprehensively Advancing the Rule of Law, adopted by the fourth Plenary Session of the 18th CPC Central Committee, clearly pointed out that to promote the whole society to establish the awareness of rule of law should start from teenagers, and the rule of law education should be incorporated into the national education system, and the curriculum of the rule of law should be set up in primary and secondary schools. The implementation of key competencies in primary and secondary schools needs to be protected by the whole society by the rule of law, which can be achieved through the following ways:

First, strengthen the cognition of the primary and secondary school principals on key competencies. Primary and secondary schools are the first principals to carry out key competency education, and they shoulder the sacred mission of implementing key competency education. Under the leadership of the primary and secondary school principals, key competencies are bound to take root.

Second, increase the guidance, transformation and business training of primary and secondary school teachers' educational concepts. Teachers are the leading force and the most important force in implementing key competencies. There is a saying, "there are no unqualified students, only unqualified teachers". The competencies of teachers often determine the competencies of students.

Third, strengthen education authorities and third party evaluation combined evaluation and assessment. In China, the leadership of the party is the key factor to solve the problem. Under the effective and forceful supervision of the main education authorities, construct new evaluation methods to promote the implementation of key competencies; in addition, the third party evaluation often plays a beneficial and complementary role, which cannot be replaced by education authorities.

\section{CONCLUSION}

With the increasing attention and importance of "key competencies" nowadays, key competencies has become an important norm in curriculum teaching. On the one hand, through the guidance of disciplinary knowledge in the teaching process, the correct direction of the teaching process is correctly grasped and a correct course is pointed out for the students to set up a correct view of time, life and values. On the other hand, key competencies are exerted by relying on the specific discipline characteristics and attractiveness of various disciplines in the specific teaching process. As the main position of moral education, moral education class, whether a new lesson or review lesson, teachers should seize the beneficial genes for students' lifelong development, pay attention to the cultivation of their comprehensive quality, and provide favorable space for the all-round development of the students while teaching the students specific knowledge and skills necessary for life. On the way forward, the previous teaching mode with specific discipline knowledge as the core should be tranformed into a new core quality system with individual human development and lifelong learning as the main objective, to practice the key competencies of disciplines, to develop the key competencies of students, and to realize the fundamental task of morality education.

\section{ACKNOWLEDGMENT}

This paper is the phased results of projects including National Social Science Fund Project "The Study of the Whole Process of Chinese Dreams Integrating into Tibetan undergraduates' Ideological and Political Education in Western Universities" (Grant No. 14XKS035), Shaanxi Provincial Social Science Association Project "Research on Cultural Confidence and the Education Approach of Shaanxi Red Culture" (Grant No. 2018ZI48), Xi'an Social Science Project "Research on the Cultivation Mechanism of Professional Psychological Quality of University Instructors in Shaanxi Province in the New Era" (Grant No. 18Y96), and the National Planning Office of Youth "Research on Causes of Youth Suicide and Its Countermeasures" (Grant No. 17BJQ01134).

Authors: He Jiangxin (1973-), Male, born in Anqing, Anhui Province, Doctor of Philosophy, Associate Professor of school of Marxism, Xi'an University of Science and Technology, Distinguished Professor of $\mathrm{Hu}$ Yang Talent Project, researcher of Xi Jinping Thought on Socialism with Chinese Characteristics for a New Era in the research center in Xi'an University of Science and Technology.

Huo Xuan (1995- ), female, Xianyang, Shaanxi, postgraduate student of Marxism of Xi'an University of Science and Technology.Contact Information: Room 1110, Office of school of Marxism, Xi'an University of Science and Technology; No.58, Middle section of Yanta Road, Xi'an, Shaanxi Province, 
Postcode: 710054

E-mail: 993689325@qq.com; Tel: 18966817026(02985583835)

\section{REFERENCES}

[1] Deng Xiaoping: Selected Works of Deng Xiaoping (Volume III) [M]. Beijing: People's Publishing House. 1993

[2] Some Opinions of the CPC Central Committee on Further Strengthening and Improving School Moral Education [EB/OL]. 1994

[3] Xin Tao, Jiang Yu, Lin Chong de. On the Connotation and Characteristics of Key Competencies of Student Development and Its Framework Orientation [J]. Chinese Education Journal. 2016

[4] Lin Chongde. Constructing the Key Competencies of Student Development in China [J]. Journal of Beijing Normal University (Social Science Edition). 2017

[5] Zhang Na. DeSeCo Project's Research and Enlightenment on Key Competencies [J]. Educational Science Research. 2013

[6] He Wei and Sheng Qunli: Towards A New Balance of Learning -Analysis of the 21st Century Learning Framework of America [J], Journal of Distance Education, 2011

[7] Zhang Hua: On the Connotation of Key Competencies [J], Global Education, 2016 